\title{
Eight Bells-Time to Change the Watch
}

TWO YEARS AGO, I wrote my first President's letter for inclusion in Oceanography. The two years has flown by; my term as TOS President coincided almost exactly with my career-capping appointment as Acting Division Director at the National Science Foundation. My dual responsibilities provided me with an unparalleled opportunity to interact with many people in the oceanographic community and an experience I will relish forever. Yet, within the next several weeks from writing this, Rick Spinrad will succeed me as President and I will succeed Eric Hartwig as Past President. And a new President-Elect will come on board. The change of watch also involves both Jim Ammerman and Vernon Asper, who have fulfilled their terms on the TOS Council and deserve acknowledgement and thanks for their services and contributions to the Society.

My goal as President was to make the Society more relevant and of greater value to its membership. The origins of TOS are rooted in bringing together and recognizing individuals from all fields of oceanography, representing the broad interests of members in research, engineering, industry, policy and education. The TOS International Ocean Research Conference, held at UNESCO Headquarters in Paris from 6-10 June 2005 was very successful in bringing several hundred oceanographers together for a stimulating and educational scientific program, thanks to the efforts of Oscar Schofield and Catherine Jeandel. And the February 2006 joint TOS/AGU/ASLO Ocean Sciences meeting in Honolulu provided a forum for one of the largest assemblages of oceanographers ever brought together. Chuck Trees did a fantastic job representing TOS on the program planning committee.
Oceanography magazine has been given a facelift, making it more eye-catching and easier to read. Ellen Kappel, Nancy Caputo, and Johanna Adams have done an exemplary job in consistently producing four highly informative, understandable, and visually exciting issues per year. Ellen has a number of special issues lined up and several unsolicited manuscripts in hand. But she is always looking for additional sponsors, themes and authors.

And the TOS web site (www.tos.org) has been revamped. The web areas devoted to the magazine are being updated regularly and include new author guidelines and an updated style guide. Work progresses on posting pdf files of back issues; more back issues are being added on a regular basis. Being able to access back issues of Oceanography is one of the requests most often heard from members.

As I have written in these letters before, TOS is facing some real challenges. Its origins revolved around the desire to highlight and promote multidisciplinary oceanography. This type of research is more so the norm now so that the niche that TOS once occupied is well filled in. I look forward to working with Rick Spinrad and the TOS Council to consider other possible niches, including perhaps observatory science and certification programs for ocean technicians.

The success of a professional society depends on its membership. As all the TOS presidents have done before me, I urge you to reach out to colleagues, friends, and students and urge them to consider membership in TOS. TOS recognizes and celebrates the full range of oceanographic interests and is open to all having an interest in oceanography.

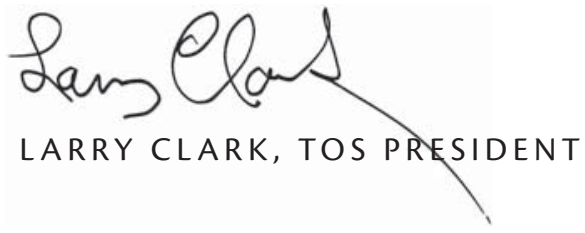

